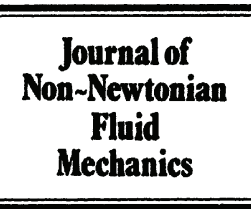

www.elsevier.com/locate/jnnfm

\title{
Extensional flow behaviour of natural fibre-filled dough and its relationship with structure and properties
}

\author{
M.F. Piteira ${ }^{\text {a }}$, J.M. Maia ${ }^{\text {b }}$, A. Raymundo ${ }^{\text {c }}$, I. Sousa ${ }^{\text {a,* }}$ \\ a Secção de Ciência e Tecnologia dos Alimentos, Instituto Superior de Agronomia, Universidade Técnica de Lisboa, \\ Tapada da Ajuda 1349-017 Lisboa, Portugal \\ ${ }^{\mathrm{b}}$ IPC-Institute for Polymers and Composites, Department of Polymer Engineering, University of Minho, 4800-058 Guimarães, Portugal \\ ${ }^{\mathrm{c}}$ Centro de Investigação em Engenharia Alimentar e Biotecnologia-ISEIT Almada, Quinta da Arreinela de Cima, 2800-305 Almada, Portugal
}

\begin{abstract}
There is an increasing awareness about the role of fibres as multifunctional substances, positively affecting the activity of the human body. From the structural point of view, insoluble fibres are known to have a strong impact on food texture. This work is part of a broader project aimed at understanding the role of fibres from different sources in traditional cookies delectableness. The impact on cookie dough characteristics, when enriched with dietary fibre, was evaluated by dynamic oscillatory tests, transient uniaxial extensional viscosity measurements and texture profile analysis. Three different sources of fibre were added: oat from cereals, orange from fruits and pea from legumes, at contents ranging from 0 to $10 \mathrm{~g}$.

In terms of processibility, there were serious difficulties in processing some of these doughs, especially those with fibre addition levels over $8 \mathrm{~g}$ for oat and orange and 9-10 g for pea. However, the results for the mechanical spectra of these doughs are similar to that of the standard dough without fibre. Tests in compression with a $4 \mathrm{~mm}$ cylinder in a $25 \mathrm{~mm}$ flask filled with dough showed to be more sensitive than oscillatory tests but still the results were somewhat difficult to interpret in terms of describing the differences in the processing behaviour of these doughs. Thus, extensional uniaxial tests were performed (for the first time in this type of materials, i.e., with no developed gluten) and showed to be suitable to describe the modification in dough structure, showing an increase of extensional viscosity for the dough with orange or oat fibre at levels of 4,8 and $10 \mathrm{~g}$, whereas for the pea fibre dough, no significant changes on the extensional behaviour were observed for formulations with up to $10 \mathrm{~g}$ of fibre, which was in general agreement with the processibility studies.
\end{abstract}

(c) 2006 Elsevier B.V. All rights reserved.

Keywords: Cookies dough; Transient uniaxial extensional viscosity; Oscillatory test; Dietary fibre; Rheology; Texture

\section{Introduction}

The health benefits of fibre consumption are well recognized. A diet low in dietary fibre is associated with a spectrum of degenerative diseases, including diabetes, obesity, coronary heart disease, bowl cancer and gallstones; it is a well-established fact that the consumption of adequate amounts of dietary fibre reduces significantly the risk of these diseases [1]. Consumer awareness of these characteristics is increasing, which is influencing their purchasing decisions, with the functional foods market increasing at about $10 \%$ a year. [2]. The challenge is to develop traditional cookies using dietary fibres for increase fibres daily intake.

In the processing of wheat-based food products, direct relationships exist between the rheological properties of dough,

\footnotetext{
* Corresponding author. Tel.: +35121 3653543; fax: +351213653200.

E-mail address: isabelsousa@isa.utl.pt (I. Sousa).
}

dough structure and quality of the finished product. Dough is the intermediate product between flour and cookies and its rheological behaviour is of considerable importance in cookies manufacture as it influences the processibility and the quality of cookies [3]. A dough which is too firm or too soft will not process satisfactorily on the appropriate dough forming equipment and will not yield a satisfactory product due to the influence on the quality of biscuits $[4,5]$.

Maache-Rezzoug et al. [6] studied the effect of principal ingredients on rheological behaviour of biscuit dough and on the quality of biscuits. They concluded that addition of sugar and fat decreases dough viscosity and relaxation time. Fat also contributes to an increase in length and to a reduction in thickness and weight of the biscuits, which were characterised by a friable crisp structure, easy to break.

Conventional oscillatory shear rheological tests usually operate in the linear region at small strains in the order of up to $1 \%$, whilst strain in gas cell expansion during proof is known to be in the region of several hundred percent [7]. Furthermore, 
Table 1

Characteristics of fibres and wheat flour (suppliers technical data sheet)

\begin{tabular}{|c|c|c|c|c|}
\hline & Fineness $(\mu \mathrm{m})$ & $\begin{array}{l}\text { Water binder capacity } \\
\left(\mathrm{gH}_{2} \mathrm{Og} \mathrm{d} \mathrm{s}^{-1}\right)\end{array}$ & $\begin{array}{l}\text { Insoluble dietary fibre content } \\
\text { (AOAC method) }(\%)\end{array}$ & $\begin{array}{l}\text { Soluble dietary fibre content } \\
\text { (AOAC method) }(\%)\end{array}$ \\
\hline Pea fibre & $90 \%<300$ & $3-5$ & 86.2 & 1.8 \\
\hline Oat fibre & $90 \%<35$ & 3.2 & 93.0 & 3.0 \\
\hline Orange fibre & $87 \%<32$ & 8.6 & 32.0 & 28.0 \\
\hline Wheat flour & $90 \%<35$ & 53.0 & 5.5 & 1.6 \\
\hline
\end{tabular}

The same batch of all raw materials was used for all the experiments.

most dynamic rheological tests are carried out in shear, whilst most large-strain deformations in dough (i.e. extrusion, sheeting, proof and baking) are extensional in nature [8].

One of the earliest attempts to characterise the fundamental rheological properties of dough were in a series of uniaxial extensional measurements by Schofield and Scott Blair in 1932 [8] that stretched a cylinder of dough floated on a mercury bath and measured the elongation and force.

In the dough sheeting and biscuit shape forming stages, the dough is passed through a laminator and a series of gauge rollers and then the cookie (dough piece) shape is cut out on a forming machine. It is obviously desirable that every dough piece should have identical weight and dimensions. Large variability in biscuit weight and thickness will cause production breakdown, problems at the close tolerance packaging stations and can also result in excessive underweight or overweight packets that violate packaging legislation [9]. Variability in both elastic recovery of the dough and anisotropic shrinkage in the sheet will distort the uniformity of the dough sheet [10].

The aim of this work is to understand the mechanical phenomena involved in fibre enriched cookies dough. Three different sources of fibre were used: cereals, fruits and legumes (oat, orange or pea). Levels of fibre incorporation (0-10 g) and the impact on dough cookies production process were studied using the textural main characteristics, oscillatory rheometry and extensional rheometry.

\section{Material and methods}

\subsection{Materials}

Cookies dough was made in a traditional way, using commercial wheat flour kindly offered by Nacional (Portugal) and fat (palm oil) graciously supplied by Fima-Lever (Portugal). Additions of fibres were made at a level of $0,4,6,8$ or $10 \mathrm{~g}$. If calculated with base of $100 \mathrm{~g}$ of flour this means fibres levels of 11.4, 18.0, 25.3 and $30.0 \mathrm{w} / \mathrm{w} \%$, respectively. This particular type of dough (for cookies) has no development of the gluten matrix.
The fibres used were pea, supplied by Cosucra and orange and oat fibre kindly supplied by Rettenmaier and Sohne $\mathrm{GmbH}+\mathrm{Co}$ (Germany). The corresponding technical data is shown in Table 1. Orange fibre is a dietary fibre, produced from carefully dried orange peel with pulp components. Oat fibre is a bright, microfine dietary fibre produced by a special process from oat bran and pea fibre is produced from pea hulls. Other ingredients used were commercial sucrose (sugar), baking powder and tap water.

The cookies dough was prepared according to the following recipe: $23 \mathrm{~g}$ sugar, $0.8 \mathrm{~g}$ baking powder, $44 \mathrm{~g}$ wheat flour and water to fulfil flour and fibre water absorption according to technical data that can be seen on Table 2 . The production process begins with the dry ingredients mixture (flour, sugar, baking powder and fibre) during the first $30 \mathrm{~s}$ of mixing, at low speed, followed by the addition of lipids $\left(45^{\circ} \mathrm{C}\right)$ and water $\left(25^{\circ} \mathrm{C}\right)$. The lipids were liquefied by gentle warming to ensure homogeneous dough [11].

\subsection{Rheological measurements}

\subsubsection{Dynamic measurements}

Rheological measurements were performed using a controlled-stress rheometer (RS-75, Haake, Germany) using a serrated parallel plate sensor $(20 \mathrm{~mm})$ to overcome the wallslip phenomena as recommended by several authors $[12,13]$ at $25 \pm 1{ }^{\circ} \mathrm{C}$. The measuring gap between the serrated plates was $1.0 \mathrm{~mm}$ and the exposed edges of the sample were covered with paraffin oil to prevent evaporation of water during measurement. Stress sweep tests were performed to determine the linear viscoelastic region. The stress range applied was of $0.1-10,000 \mathrm{~Pa}$, with a constant frequency of $1 \mathrm{~Hz}$. The frequency sweep tests were set up inside the viscoelastic region, in a frequency range of $10^{-2}-10^{4} \mathrm{~Hz}$. The determinations were replicated at least three times. Despite the use of serrated plates, the average error of the three measurements performed for each material was still relatively large (up to almost $15 \%$ in some cases), as shown in Table 3. This error was especially seen at high frequencies, which is an indication that slip may not have been prevented completely.

Table 2

Water addition to doughs with fibre

\begin{tabular}{|c|c|c|c|c|c|c|c|c|c|c|}
\hline \multirow[t]{2}{*}{ Fibre level (g) } & \multirow{2}{*}{$\begin{array}{l}0 \\
-\end{array}$} & \multicolumn{3}{|l|}{4} & \multicolumn{3}{|l|}{8} & \multicolumn{3}{|l|}{10} \\
\hline & & Pea & Oat & Orange & Pea & Oat & Orange & Pea & Oat & Orange \\
\hline Water amount (g) & 9.0 & 11.8 & 11.9 & 16.2 & 14.6 & 14.8 & 23.4 & 16.0 & 16.3 & 27.0 \\
\hline
\end{tabular}


Table 3

Average error in oscillatory measurements

\begin{tabular}{|c|c|c|c|c|c|c|c|c|c|c|}
\hline \multirow[t]{2}{*}{ Fibre level (g) } & \multirow[t]{2}{*}{0} & \multicolumn{3}{|l|}{4} & \multicolumn{3}{|l|}{8} & \multicolumn{3}{|l|}{10} \\
\hline & & Pea & Oat & Orange & Pea & Oat & Orange & Pea & Oat & Orange \\
\hline Error in $G^{\prime}(\%)$ & 12.0 & 7.0 & 3.3 & 9.6 & 14.6 & 0.8 & 3.0 & 6.1 & 3.6 & 2.2 \\
\hline Error in $G^{\prime \prime}(\%)$ & 9.4 & 7.8 & 7.0 & 11.8 & 13.6 & 0.9 & 5.0 & 8.5 & 5.9 & 3.2 \\
\hline
\end{tabular}

Preliminary gap selection was made from the time sweep curves of the control dough (without fibre incorporation), traced with the following gap range: $0.5,1.0,1.5$ or $2.0 \mathrm{~mm}$. Kinetic tests were set up inside the viscoelastic region $(60 \mathrm{~Pa})$, at a frequency of $1 \mathrm{~Hz}$ during $10 \mathrm{~h}$ at $5^{\circ} \mathrm{C}$. The determinations were replicated at least three times. The best repeatability curves were those traced with a $1 \mathrm{~mm}$ gap.

\subsubsection{Texture measurements}

The textural variable firmness was obtained from the textural profile analysis carried out in a texturometer TA-XT2 (Stable Micro Microsystems, UK). Penetration tests were performed in the dough using a cylindrical stainless steel probe of $4 \mathrm{~mm}$ diameter $(15 \mathrm{~mm}$ of penetration and $1 \mathrm{~mm} / \mathrm{s}$ of crosshead speed). Dough was contained in a cylindrical flask with $2.5 \mathrm{~cm}$ diameter and $4.5 \mathrm{~cm}$ height. After penetrating the sample, the probe returned during $5 \mathrm{~s}$ to a position above the platform surface. From the force versus time data the maximum force (correlated with firmness) was calculated. These determinations were conducted at $20 \pm 1{ }^{\circ} \mathrm{C}$ in a temperature controlled room and were replicated five times. The error was first calculated in a test on 10 samples of the standard dough without fibres and was found to be less than $5 \%$.

\subsubsection{Extensional measurements}

Extensional flows or, more generally, shear-free flows are, in principle, very sensitive to the morphology present in multiphase materials and dough is not an exception. For example, the foaming process upon baking is essentially a biaxial extensional deformation while during dough mixing uniaxial extension and/or compression play a major role. Amongst the relevant reports in the literature on shear-free flows of doughs in general are those of Bloksma [14], based on alveograph-type techniques, Uthayakumaran et al. $[15,16]$, based on uniaxial extension, Bagley et al [17] based on uniaxial compression and Dobrasczyk [18] and Charalambides et al. [19,20] based on the bubble-inflation technique, but all deal with systems in which the dough shows gluten development, which is not the case in this work.

In order to assess (to the best knowledge of the authors for the first time) the true extensional flow behaviour of the cookies dough without gluten development and due to the lack of a suitable bubble-inflation apparatus, the results of which could be more or less directly related to the foaming process and foam stability, a uniaxial extensional rheometer was used. Since the changes in interfacial area are very large in uniaxial extension, it is hoped that although not as suitable for process simulation as bubble-inflation, the results in this type of flows will still be highly sensitive to the interactions between the dough and the fibres.

The rheometer used here consists of a modification to a commercial rotational rheometer (TA Instruments Weissenberg Rheogoniometer) as described elsewhere (e.g. [21,22]) and works according to a "half-Meissner" principle. However, since this was the first time it was used with dough, a short analysis of the technique and the potential sources for errors/inaccuracies with these materials follows below.

Fig. 1 depicts the general lay-out of the rheometer. If one assumes homogeneous extension, then the theoretical strain rate is given by:

$\dot{\varepsilon}=\frac{\Omega R_{\mathrm{r}}}{L}$

where $\Omega$ and $R_{\mathrm{r}}$ are the angular speed and radius of the rollers, respectively, and $L$ is the sample length.

The tensile stress is given by:

$\sigma_{11}-\sigma_{22}=\frac{M(t)}{\pi R_{\mathrm{r}} R(t)}$

where $M(t)$ and $R(t)$ are the measured torque and sample radius, respectively.

Also, the radius evolution in time can be described as

$R(t)=R_{0} \mathrm{e}^{-\dot{\varepsilon} t / 2}$

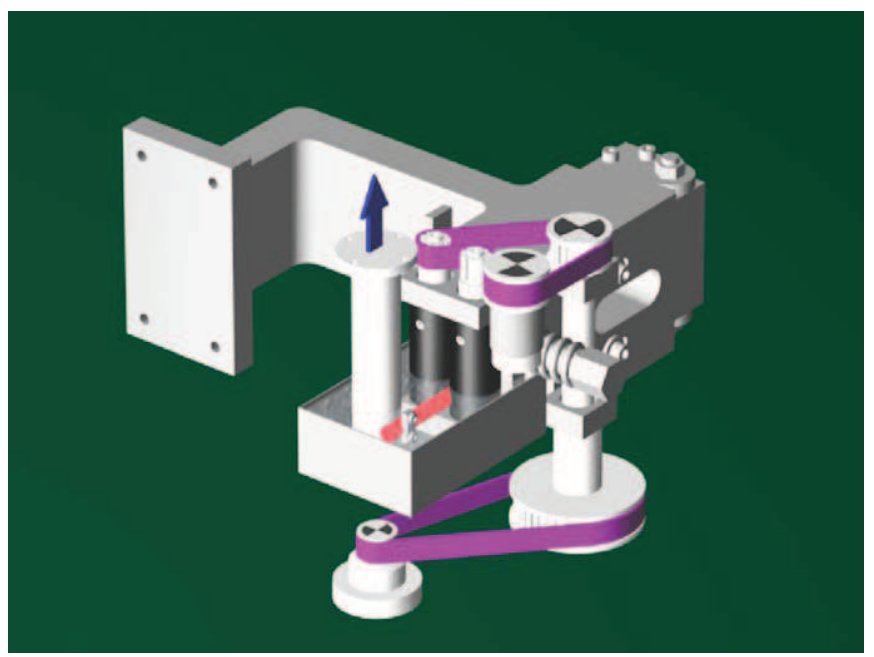

Fig. 1. General lay-out of rheometer. The bottom plate rotates at a given speed and the movement is transmitted to the counter-rotating rollers via a shaft. The torque is measured at the clamped end of the sample. For high temperature work, the sample is immersed in a heated bath. 


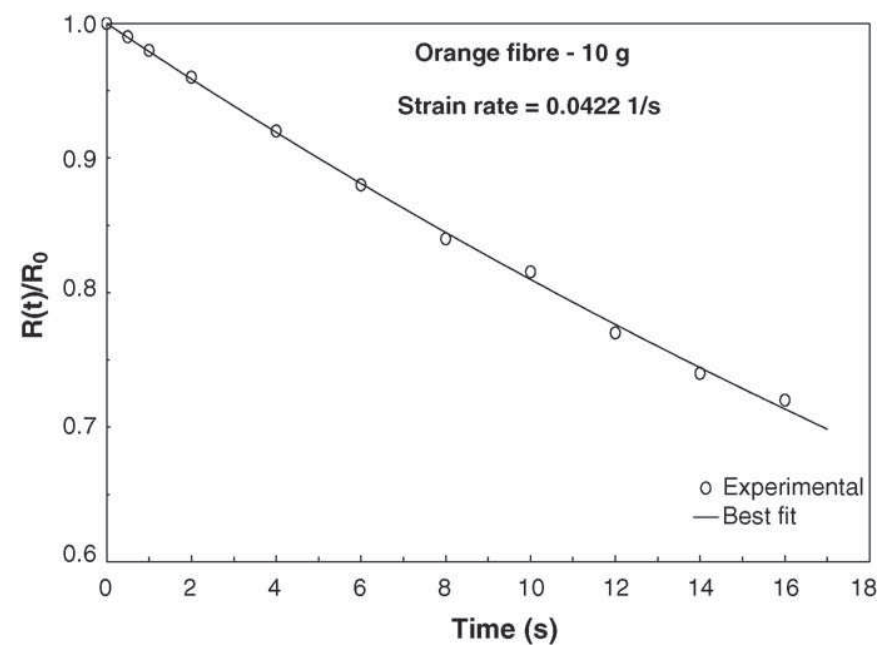

Fig. 2. Calculation of true strain rate-fit to reduced radius evolution at the rollers.

where $R_{0}$ is the initial sample radius. Eq. (3) is very important because, as shown in Barroso et al. [22], due to a number of factors, the real strain rate is not usually equal to the theoretical strain rate given by Eq. (1). Thus, the true strain rate is evaluated by fitting an exponentially decaying function to the evolution of the sample radius in time (monitored using a digital video camera) close to the rollers, as is usual in this type of rheometers [22]. In this particular case, the evaluation was performed at both the mid-point of the sample and a distance of $0.5 \mathrm{~L} / \mathrm{D}$ from the rollers; the results were found to vary by less than $5 \%$ between them, with a typical fit being shown in Fig. 2, for the $10 \mathrm{~g}$ of orange fibre sample.

As explained in Barroso et al. [22], this technique yields very accurate results, generally with a deviation lower than $10 \%$, provided certain experimental precautions are taken, namely in what concerns sample preparation and homogeneity of the deformation.

In what regards sample preparation, the dough was produced according to the same method as for the oscillator tests, cylindrical rods being prepared manually between two plates, with special care being taken to reject those that were not perfectly cylindrical (within visual error) or had pockets of air trapped inside. Upon loading onto the rheometer, residual stresses were allowed to relax, which was followed by the removal of any existing slack, another waiting period for residual stress relaxation; once this happened the experiment could be started. The effective length of each sample was $40 \mathrm{~mm}$ and the radius varied between 2 and $3 \mathrm{~mm}$, thus yielding an aspect ratio, $L / D$, ranging between approximately 7 and 10 .

In terms of deformation homogeneity, the main issue is related to the boundary conditions, since the sample is compressed at the ends, thus changing the cross section from circular to approximately planar [23]. However, as shown in Barroso et al. [22], provided the clamping force is low enough not to crunch the sample (which is ensured by the use of a suitable spring) and aspect ratio of the sample is higher than an experimentally determined value (in the present case approximately 5) the effect of

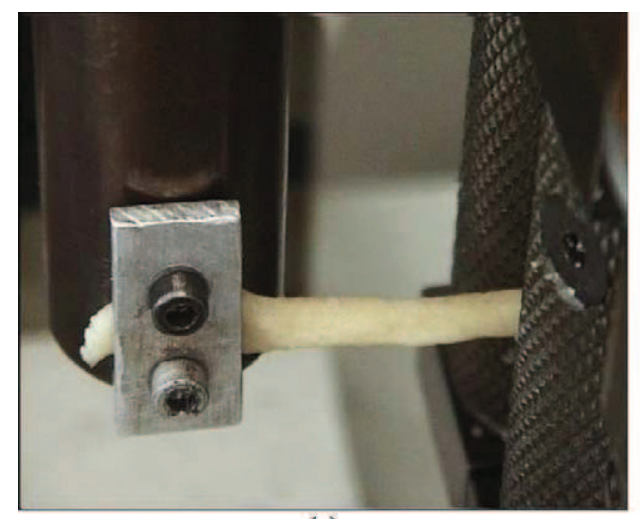

(a)

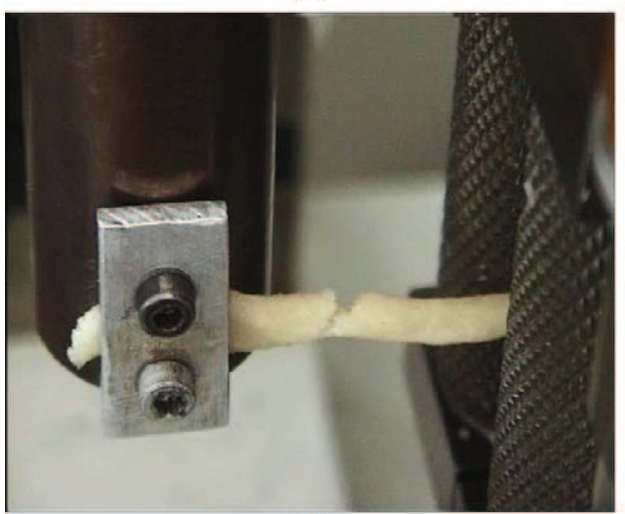

(c)

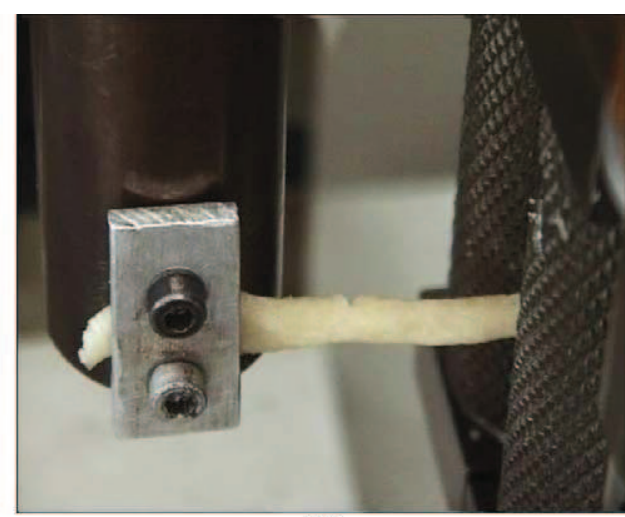

(b)

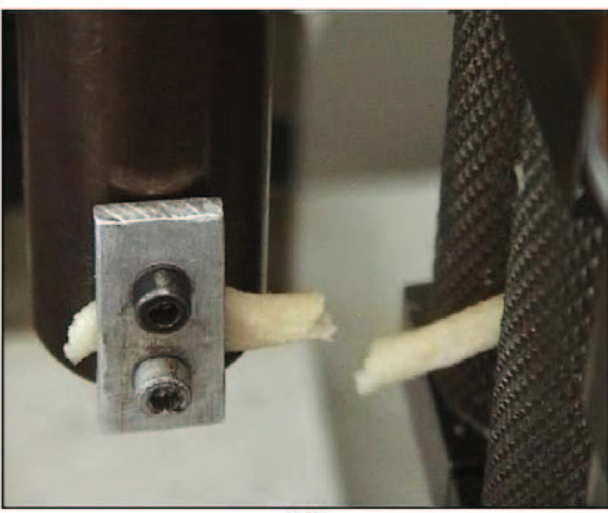

(d)

Fig. 3. Flow and rupture of cookie dough after homogeneous deformation ( $8 \mathrm{~g}$ pea): (a) $16 \mathrm{~s}$ after start; (b) $18 \mathrm{~s}$ (beginning of rupture); (c) $23 \mathrm{~s}$; (d) $28 \mathrm{~s}$. 
the non-circular constant cross section at the clamps becomes negligible. In addition, in these materials (and in opposition to some polymeric materials), the deformation is homogeneous and the cross-section remains constant up to sample rupture (except close -0.2 to $0.5 L / D$ away from the clamp), as can be seen in Fig. 3 for the sample with $8 \mathrm{~g}$ pea fibre.

All the tests were performed at room temperature after keeping the dough at $5{ }^{\circ} \mathrm{C}$ during $10 \mathrm{~h}$, the time necessary to stabilize it. Due to the high viscosity and self-supportability of the samples, no specific supporting media, e.g., oil, was used. Several experiments were performed for each material and only data from those that yielded homogeneous deformation and constant strain rate were used.

\subsection{Statistical analysis}

The results were analysed in terms of ANOVA post-hoc comparisons, Sheffé contrast test with a significance level of $p<0.05$, using the program STATISTICA from StatSoft, version 5.0.

\section{Results and discussion}

\subsection{Maturation kinetics of dough}

The cookies dough maturation kinetic was traced with a gap of $1.0 \mathrm{~mm}$, inside the viscoelastic region $(60 \mathrm{~Pa})$, at a frequency of $6.28 \mathrm{rad} / \mathrm{s}(1 \mathrm{~Hz})$ throughout enough time to allow for dough equilibrium. Fig. 4 shows that dough became stable after approximately $10 \mathrm{~h}$. At this time scale kinetic maturation must be studied at $5^{\circ} \mathrm{C}$ to avoid dough decay.

\subsection{Oscillatory tests}

The storage $\left(G^{\prime}\right)$ and loss $\left(G^{\prime \prime}\right)$ moduli for cookies dough were measured over a range of frequency at $25^{\circ} \mathrm{C}$ since this is the dough processing temperature, with a previous stabilization time of at least $10 \mathrm{~h}$ at $5^{\circ} \mathrm{C}$ in a refrigerator.

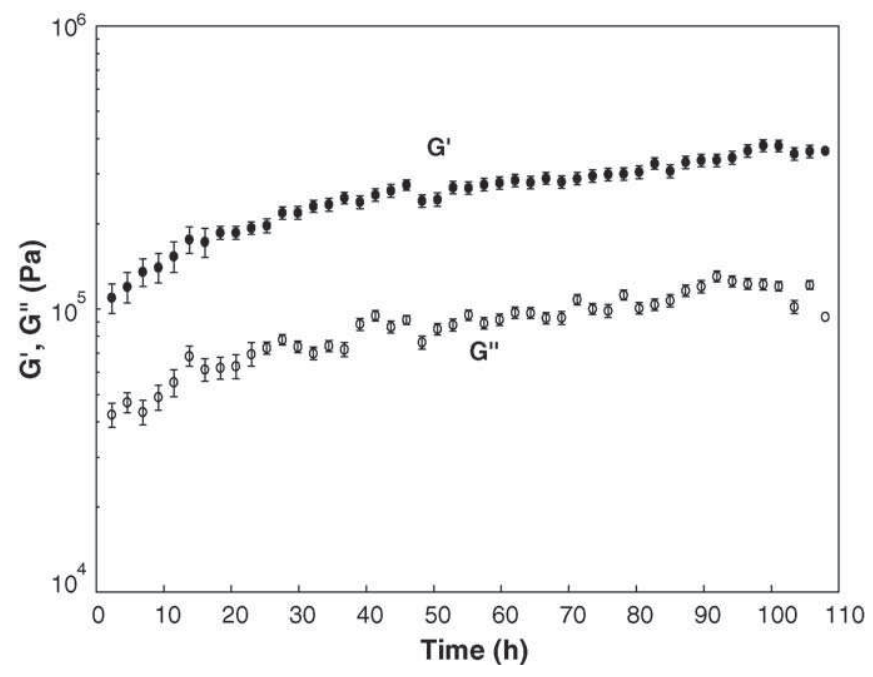

Fig. 4. Maturation kinetic of the control dough, gap $1.0 \mathrm{~mm}$, shear stress $60 \mathrm{~Pa}$, frequency $1 \mathrm{~Hz}$ and temperature $5^{\circ} \mathrm{C}$.

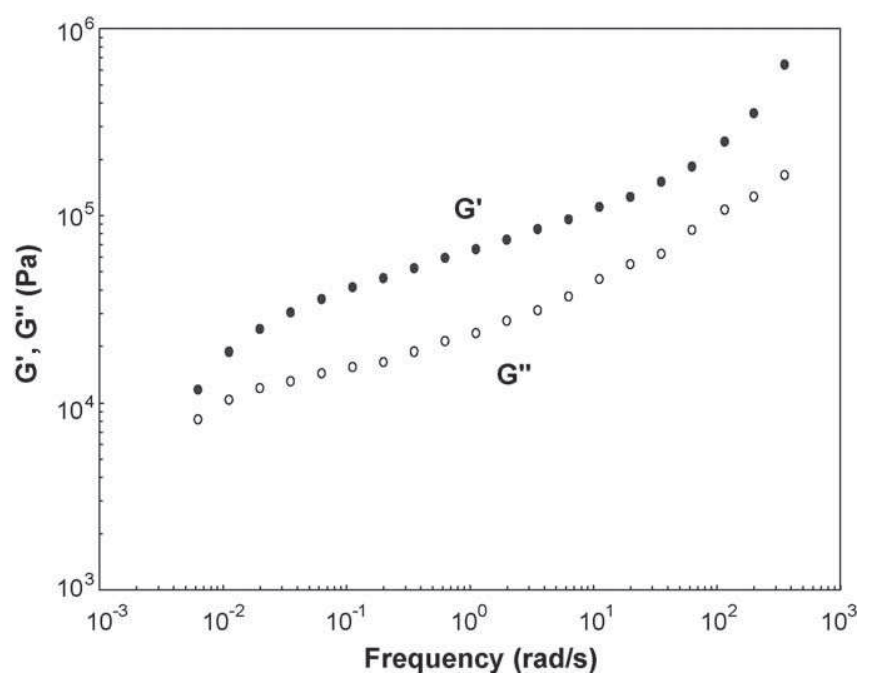

Fig. 5. Mechanical spectra of cookies dough without fibre, gap $1.0 \mathrm{~mm}$, shear stress $60 \mathrm{~Pa}$ and temperature $25^{\circ} \mathrm{C}$.

Fig. 5 shows the frequency spectra of the cookie dough without fibre (control dough) at $25^{\circ} \mathrm{C}$. This dough shows a response typical of a cross-linked polymer network, i.e. the storage modulus $G^{\prime}$ was higher than the loss modulus $G^{\prime \prime}$ at any given frequency which is a characteristic of viscoelastic solids. This is in agreement with studies of many authors for the bread dough, with both moduli $G^{\prime}$ and $G^{\prime \prime}$, being highly frequency dependent [24-29].

In terms of oscillatory dynamic measurements, the addition of pea fibre did not induce significant $(p>0.05)$ changes, within the experimental error, the moduli being similar to those of the control dough, as shown in Fig. 6a) (only for the dough without fibre and with $10 \mathrm{~g}$ for the sake of readability). Again, the storage modulus $\left(G^{\prime}\right)$ was always higher than the loss modulus $\left(G^{\prime \prime}\right)$ in the frequency range studied and both are frequency dependent. The dough with 4 or $8 \mathrm{~g}$ of pea fibre presented a tendency to higher values for both moduli than the control; while cookies dough with $10 \mathrm{~g}$ presented tendency to smaller values. However, again, those differences are not significant with $\mathrm{p}$ values over 0.05 . As mentioned before, the variability of the results at high frequencies is relatively large and is probably due to slip of the material, despite the use of serrated plates.

Fig. 6(b) and (c) show the frequency spectra of cookies dough with oat and orange fibre (again for $10 \mathrm{~g}$ of fibre and the control dough without fibre) at $25^{\circ} \mathrm{C}$, respectively. Again, these cookies dough present a strong viscoelastic response. An increase in $G^{\prime}$ and $G^{\prime \prime}$ with frequency was observed in all cases but maintaining the predominant elastic character. In general, and again within experimental error, the cookies dough enriched with oat and orange fibres showed values of $G^{\prime}$ and $G^{\prime \prime}$ that were significantly similar to those of the control dough.

In short, the addition of fibres (orange, oat and pea) at levels of 4, 6, 8 and $10 \mathrm{~g}$, do not affect significantly the linear viscoelastic behaviour of the dough (Fig. 7). However, in practice there have been processibility problems (see Fig. 8) in processing cookies dough with fibre addition over the level 

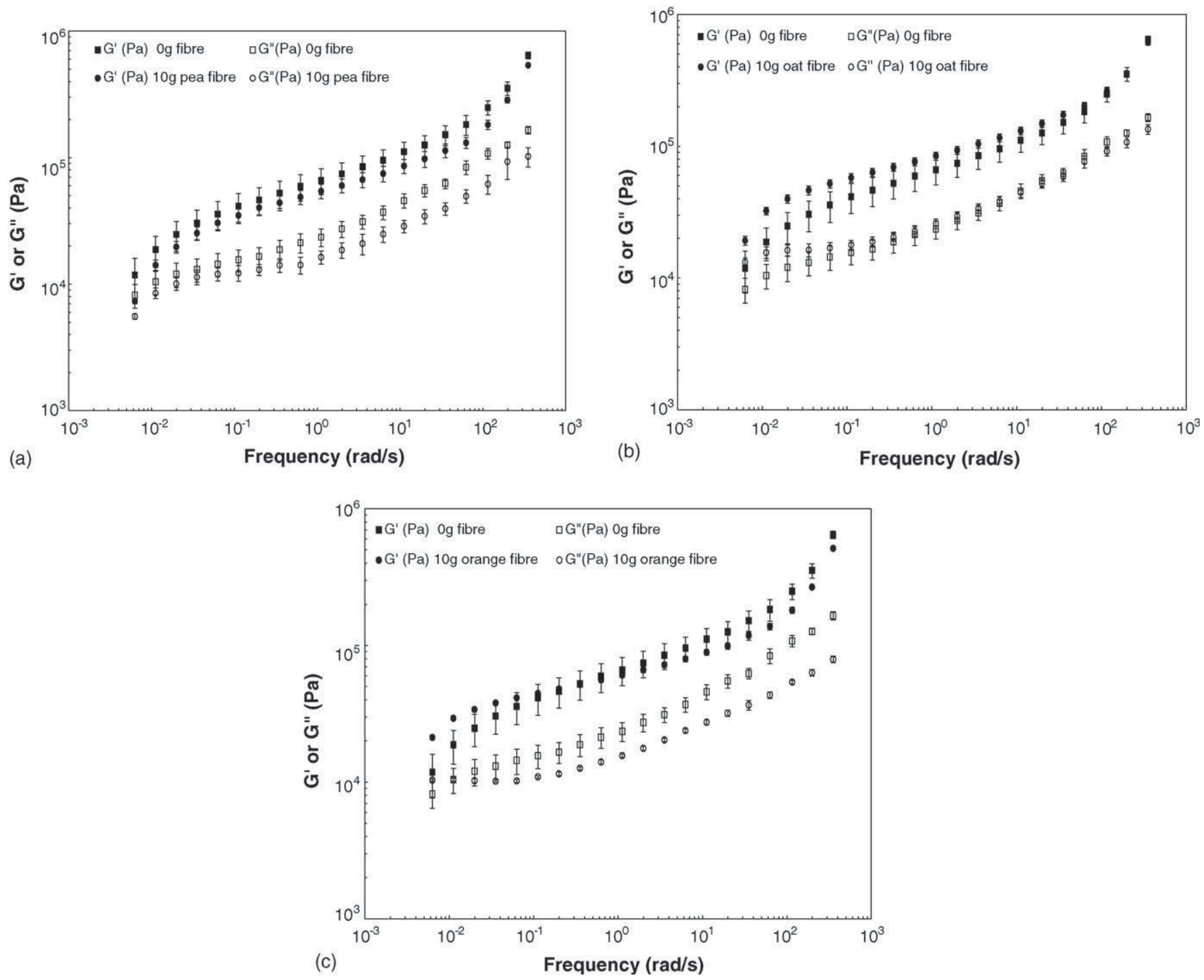

Fig. 6. Mechanical spectra of the dough without fibre and with $10 \mathrm{~g}$ of: (a) pea, (b) oat and (c) orange fibres. Same conditions as in Fig. 5.

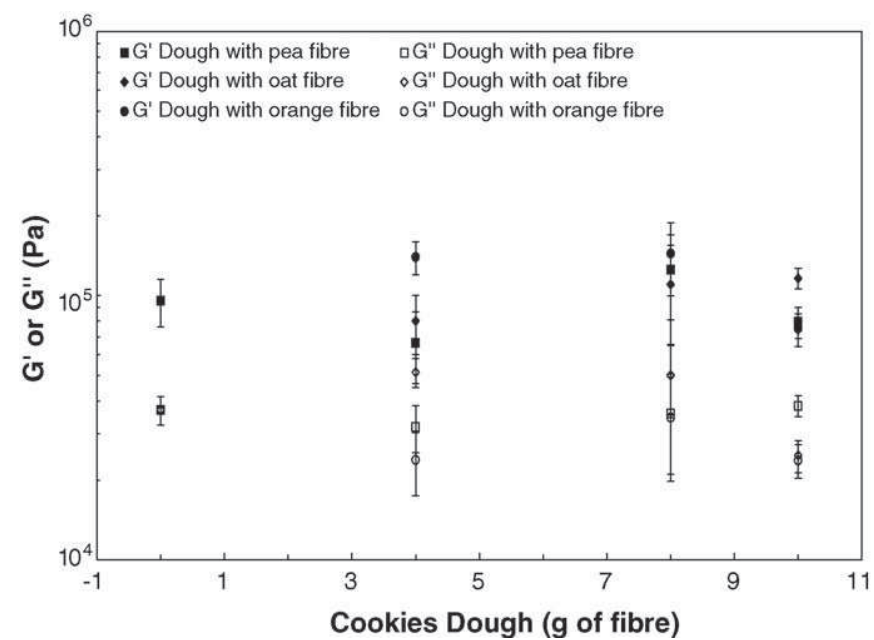

Fig. 7. $G^{\prime}$ and $G^{\prime \prime}$ moduli obtained from the mechanical spectra at $1 \mathrm{~Hz}$ of the cookies dough with $4,6,8$, or $10 \mathrm{~g}$ of pea, oat or orange fibre and from the control dough, gap $1.0 \mathrm{~mm}$, at $25^{\circ} \mathrm{C}$.

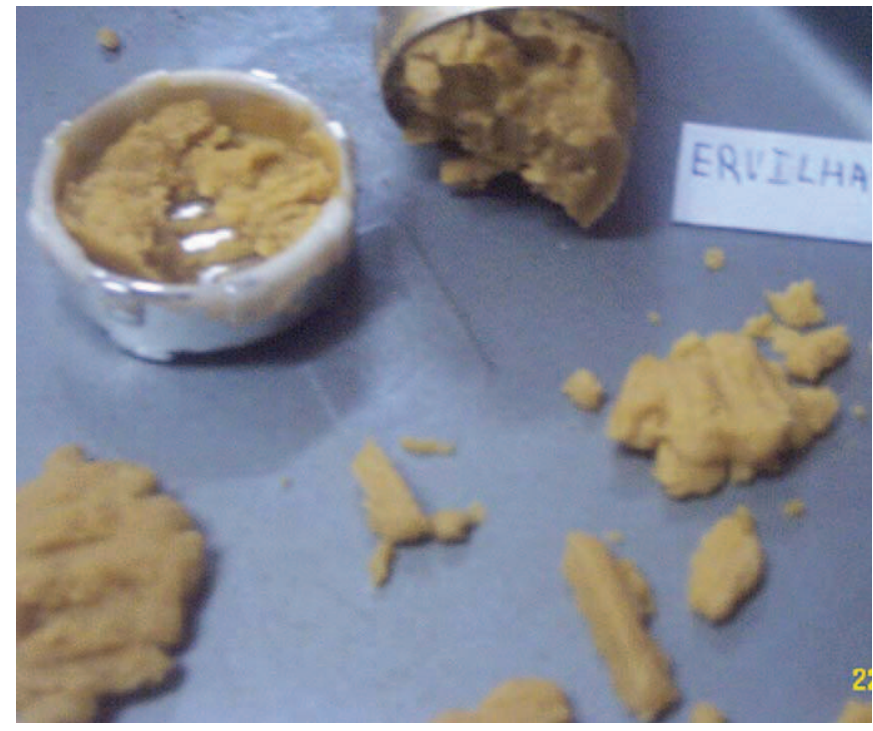

Fig. 8. Pea dough cookies with a fibre level of $10 \mathrm{~g}$ showing processibility problems. 
Table 4

Average values of dough firmness (analysed by ANOVA/MANOVA post-hoc Scheffé contrasts)

\begin{tabular}{ll}
\hline Cookies dough & Firmness $(N) \pm$ S.D. \\
\hline $0 \mathrm{~g}$ Fibre & $0.7 \pm 0.08 \mathrm{~b}, \mathrm{c}$ \\
Cookies dough with pea fibre & $1.0 \pm 0.15 \mathrm{~d}, \mathrm{f}$ \\
$4 \mathrm{~g}$ & $0.3 \pm 0.04 \mathrm{a}$ \\
$8 \mathrm{~g}$ & $0.5 \pm 0.04 \mathrm{a}, \mathrm{b}$ \\
$10 \mathrm{~g}$ & \\
Cookies dough with oat fibre & $1.1 \pm 0.14 \mathrm{e}, \mathrm{g}, \mathrm{h}, \mathrm{f}, \mathrm{j}$ \\
$4 \mathrm{~g}$ & $1.4 \pm 0.11 \mathrm{i}, \mathrm{j}, \mathrm{k}$ \\
$8 \mathrm{~g}$ & $1.4 \pm 0.02 \mathrm{k}$ \\
$10 \mathrm{~g}$ & \\
Cookies dough with orange fibre & $0.9 \pm 012 \mathrm{~d}, \mathrm{e}$ \\
$4 \mathrm{~g}$ & $1.1 \pm 0.13 \mathrm{e}, \mathrm{f}, \mathrm{g}, \mathrm{h}, \mathrm{I}$ \\
$8 \mathrm{~g}$ & $1.0 \pm 0.08 \mathrm{~d}, \mathrm{~g}$ \\
$10 \mathrm{~g}$ & \\
\hline
\end{tabular}

All the results had a percentage of error less than $5 \%$.

of $8 \mathrm{~g}$ for oat and orange fibre and $10 \mathrm{~g}$ for the pea fibre [11] which means that the oscillatory tests were not suitable to adequately discriminate the modifications on cookies dough structure and characteristics introduced by the fibre addition.

\subsection{Texture measurements}

In Table 4 and Fig. 9 one can see that all the cookies dough with $4 \mathrm{~g}$ of fibres (pea, oat and orange) show significantly $(p<0.05)$ higher firmness than the control dough without fibre and, in general, the firmness tends to increase with fibre content. Interestingly, the fibres that yield the highest firmness values are the oat fibres, followed by the orange ones and finally the pea fibres (in this case the values of firmness are, in general, even below those of the control dough. Nevertheless, the results at $4 \mathrm{~g}$ of fibre showed a considerable dispersion.

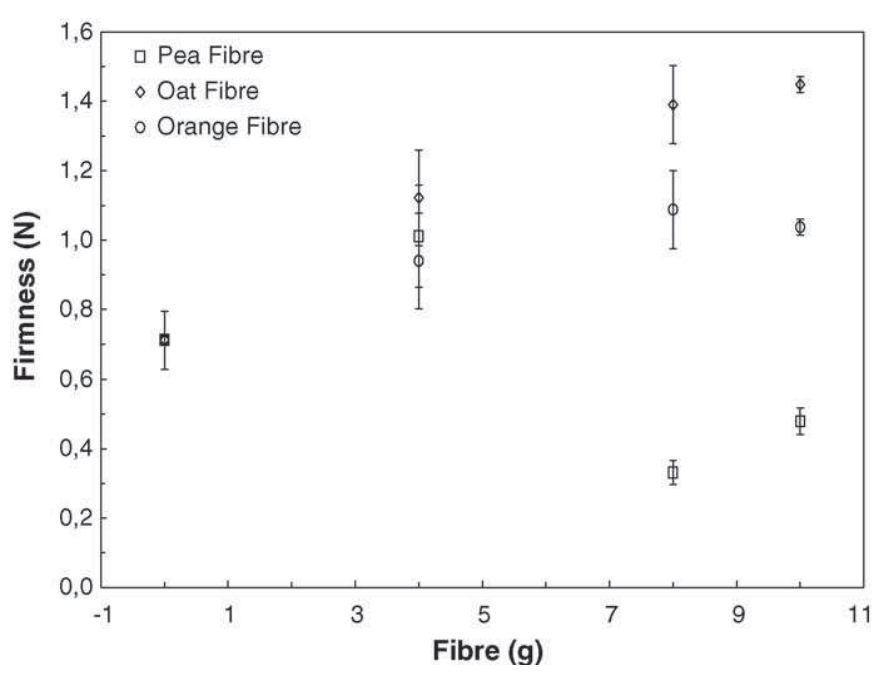

Fig. 9. Average values of cookies dough firmness: control dough and dough with $4,6,8$, or $10 \mathrm{~g}$ of fibres (pea, oat or orange).

\subsection{Uniaxial extensional flow}

As already mentioned, the extensional viscosity measurements were very difficult to perform due to the fragility of the cookies dough and their heterogeneity, (this, for example, made sample preparation a very difficult and time consuming procedure) and only data from those experiments that yielded homogeneous deformation under a constant strain rate was used. Even for homogeneous samples (the only ones used in the measurements), it was impossible to achieve steady-state due to loss of cohesiveness of the cookies dough at total Hencky strains of ranging from 0.5 to 0.7 . For this reason, all the results are depicted in the form of transient uniaxial extensional viscosity. All tests were performed until physical rupture of the samples, as shown in Fig. 3.

Fig. 10(a)-(c) depict the transient extensional viscosity of the different cookies dough. The base material, i.e., the plain dough, shows a slightly strain-softening behaviour, since the data slopes as approximately 0.85 in opposition to 1 as would be the case for sufficiently low times after the inception of the deformation and before the attainment of the steady-state value of $3 \eta_{0}$.

\subsubsection{Cookies dough with pea fibre}

Pea fibre incorporation in the cookies dough does not seem to affect (Fig. 10a) the dough uniaxial transient flow at strains above approximately 0.1 . On the contrary, between approximately 0.01 and 0.1 strain units, there seems to be a decrease of the transient extensional viscosity with increasing incorporation content. This effect may be due to a deficient wetting of the fibres by the dough due to the eventual formation of weak clusters of fibres due to fact that the pea fibres have a relatively low water binding capability and are relatively long (lengths of the order of $300 \mu \mathrm{m}$ ) when compared with the flour dimensions (about $35 \mu \mathrm{m}$ ); at longer times (in excess of approximately $10 \mathrm{~s}$ ) these clusters are destroyed and any differences between the fibre incorporation contents disappear (within experimental error).

Studies on the effect of the fibre addition on the alveoghaph characteristics of wheat flour, show that the addition of pea fibre yielding a reduction of about $42 \%$ in the extensibility of the wheat flour [30] showing the same tendency found in this study.

\subsubsection{Cookies dough with oat fibre}

Fig. 10b depicts the transient extensional viscosity of cookies dough with oat fibre for 4,8 , and $10 \mathrm{~g}$ and for the control dough without fibre. The dough with oat fibres had similar extensional properties for all the fibres levels under study $(4,8$ and $10 \mathrm{~g}$ ) and showed an approximately Newtonian behaviour, i.e., a slope of approximately 1, which equates into an increase in transient extensional viscosity when compared to the control dough. Similarly to what happened with pea fibres, it seems that cookies dough with the higher level of oat fibre $(10 \mathrm{~g})$ shows a slightly lower extensional viscosity than that with 4 and $8 \mathrm{~g}$ at total strains between 0.04 and 0.25 . This again points to the formation of deficiently wetted clusters of fibres; since oat fibres have similar fineness to wheat flour these clusters are smaller and weaker than those observed for the pea fibres, which explains the fact that this effect is only observed at very high fibre contents $(10 \mathrm{~g})$. 

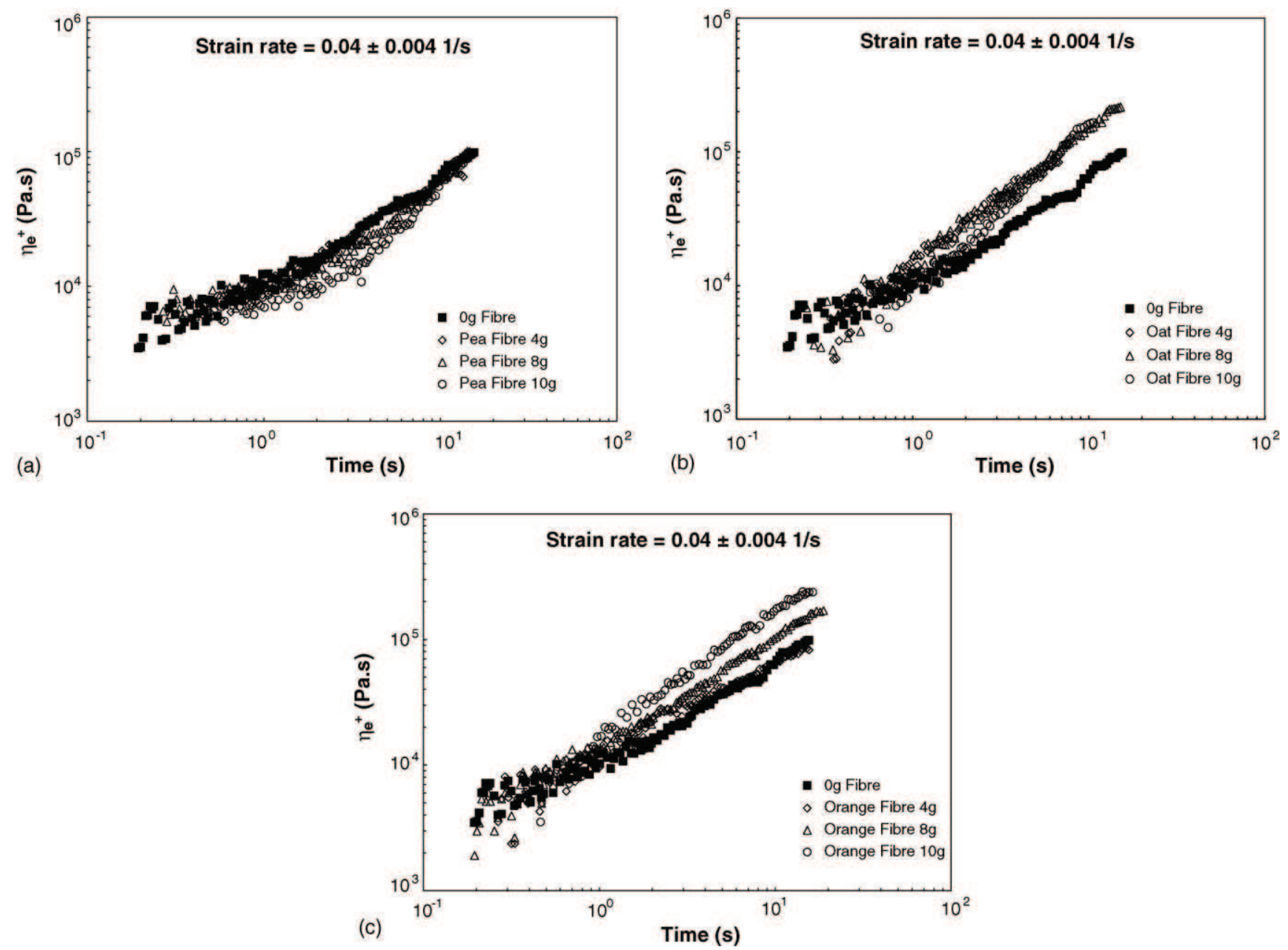

Fig. 10. Transient extensional viscosity for uniaxial extension of the cookies dough with (a) pea, (b) oat and (c) orange fibre for the control dough without fibres and incorporations of 4,8 or $10 \mathrm{~g}$. Strain rate as indicated.

\subsubsection{Cookies dough with orange fibre}

Contrarily to the previous cases, the enrichment of the cookies dough with orange fibre yields an increasing level of strainhardening with fibre incorporation (Fig. 10c). The main difference between the oat and the orange fibres was the composition on insoluble and soluble fibres. The orange fibres have a soluble fibre level of $28 \%$ ( $18.6 \%$ of pectin) and the oat fibres only $3 \%$. Previous studies [30] made in dough enriched with inuline fibre (which have similar soluble fibre levels than orange fibres) had concluded that the dough resistance to deformation (tenacity) increased with the addition of inuline fibre due to interactions between the polysaccharides from the fibres and proteins from wheat flour [31]. Thus, it is quite feasible that additions of those kinds of fibres with high levels of soluble fibre promote the firmness of the dough due to the network developed and prevent the weak clusters of fibres observed for fibres with lower soluble fibre levels (such as oat and pea) from forming in the dough.

\section{Conclusions}

The main purpose of this work was to understand the mechanical phenomena involved with fibre enriched cookies dough. In order to do so, three different sources of fibre (cereals, fruits and legumes) were used and different levels of fibre incorporation $(0-10 \mathrm{~g})$ tested. The impact on dough cookies production process was studied using the textural main characteristics and oscillatory and, for the first time for this type of systems (dough without gluten development), uniaxial extensional rheometry.

From the texture analysis we may observe that the firmness tends to increase with fibre content, although there were some exceptions showing a higher lever of results dispersion.

The results show that extensional uniaxial viscosity is a more sensitive method to study the dough rheology than the oscillatory tests, clearly showing differences when different types of fibre are incorporated in cookies dough. Furthermore, these results are in agreement with the processibility studies, which show that it was very difficult to process these doughs at levels of fibre addition equal or above $8 \mathrm{~g}$ for oat and orange and 9-10 $\mathrm{g}$ for pea, since higher viscosity levels lead to an increased difficulty in the formation of the cellular structure in the final biscuits. Thus, although all the formulations presented a typical mechanical behaviour for cookies dough, the pea fibre formulation seems to be better suited for cookie enrichment, since it is possible to use this dietary fibre as a functional ingredient at levels up to $10 \mathrm{~g}$ and still produce cookies within the standards. 


\section{References}

[1] J. Sidhu, N. Suad, Al-Hooti, J.M. Al Saqer, Effect of adding whea bran and germ fractions on the chemical composition of high-fibber toast bread, Food Chem. 67 (1999) 365.

[2] H. Bollinger, Consumer expectations and eating behaviour over time, Food Market. Technol. 15 (5) (2001) 10.

[3] R.S. Manohar, P.H. Rao, Interrelationship between rheological characteristic of dough and quality of biscuits; use of elastic recovery of dough to predict biscuit quality, Food Res. Int. 35 (2002) 807.

[4] P. Wade, Preparation of Biscuit Dough, in Biscuits, Cookies and Crackers. The Principles of the Craft, vol. 1, Elsevier Applied Science, London, 1988 (chapter 18).

[5] D.J.R. Manley, in: Ellis Horwood (Eds.), Technology of Biscuits, Crackers and Cookies, Chichester, 1983 (chapter 3).

[6] Z. Maache-Rezzoug, J.-M. Bouvier, K. Allaf, C. Patras, Effect of principal ingredients on rheological behaviour of biscuit dough and quality of biscuits, J. Food Eng. 35 (1998) 23.

[7] J.I. Amemiya, J.A. Menjivar, Comparison of small and large deformation measurements to characterise the rheology of wheat flour dough, J. Food Eng. 16 (1992) 91.

[8] B.J. Dobraszczyk, M.P. Morgenstem, Rheology and the breadmaking process, J. Cereal Sci. 38 (2003) 229.

[9] R. Lawson, Oven control systems to reduce packet weight tolerance in biscuits manufacture, Baking Indus. J. 8 (1975) 7.

[10] P. Wade, Technology of biscuit manufacture: investigation of the process for making sweet biscuits, Chem. Indus. 6 (1971) 284

[11] M.F. Piteira, A. Raymundo, I. Sousa, Gum and Stabilisers for the food industry, in: P.A. Williams, G.O. Phillips (Eds.), Effect of Principal Ingredients on Quality of Cookies with Dietary Fibre, vol. 12, Royal Society of Chemistry, Cambridge, 2004, p. 475.

[12] H.A. Barnes, J.F. Hutton, K. Walters, An Introduction to Rheology, Elsevier Science Publishers B.V., Netherlands, 1989, pp. 40-73.

[13] J. Franco, A. Raymundo, I. Sousa, C. Gallegos, Influence of processing variables on the rheological and textural properties of lupin protein-stabilized emulsions, J. Agric. Food Chem. 46 (1998) 3109.

[14] A.H. Bloksma, A calculation of the shape of the Alveograms of some model rheological substances, Cereal Chem. 34 (1957) 126.

[15] S. Uthayakumaran, M. Newberry, K. Keentok, F.L. Stoddard, F. Bekes, Basic rheology of bread dough with modified protein content and glutenin-to-gliadin ratios, Cereal Chem. 77 (2000) 744.
[16] S. Uthayakumaran, M. Newberry, N. Phan-Thien, et al., Small and large strain rheology of wheat gluten, Rheol. Acta 41 (1) (2002) 162.

[17] E.B. Bagley, D.D. Christianson, J.A. Martindale, Uniaxial compression of a hard wheat-flour dough-data-analysis using the upper convected Maxwell model, J. Texture Stud. 19 (3) (1988) 289.

[18] B.J. Dobraszczyk, The physics of baking: rheological and polymer molecular structure-function relationships in breadmaking, J. NonNewtonian Fluid Mech. 124 (1-3) (2004) 61.

[19] M.N. Charalambides, L. Wanigasooriya, J.G. Williams, Biaxial deformation of dough using the bubble inflation technique, I. Exp. Rheol. Acta 41 (6) (2002) 532.

[20] M.N. Charalambides, L. Wanigasooriya, J.G. Williams, Biaxial deformation of dough using the bubble inflation technique II. Numerical modelling, Rheol. Acta 41 (6) (2002) 541.

[21] J.M. Maia, J.A. Covas, J.M. Nóbrega, T.F. Dias, F.E. Alves, Measuring uniaxial extensional viscosity using a modified rotational rheometer, J. Non-Newtonian Fluid Mech. 80 (1999) 183.

[22] V.C. Barroso, J.A. Covas, J.M. Maia, Sources of error and other difficulties in extensional rheometry revisited: commenting and complementing a recent paper by T. Schweizer, Rheol. Acta 41 (1/2) (2002) 154.

[23] R.W. Connelly, L.J. Garfield, G.H. Pearson, Local stretch history of fixed-end-constant-length-polymer-melt stretching experiment, J. Rheol. 23 (1979) 651.

[24] G.E. Hibberd, W.J. Wallace, Dynamic viscoelastic behaviour of wheatflour doughs. I. Linear aspect, Rheol. Acta 5 (1966) 193.

[25] J.R. Smith, T.L. Smith, N.W. Tschoegl, Rheological properties of wheat doughs. III. Dynamic shear modulus and its dependence on amplitude, frequency and dough composition, Rheol. Acta 9 (1970) 239.

[26] D.B. Cumming, M.A. Tung, Modification of the ultrastrure and rheology of rehydrated commercial wheat gluten, Can. Inst. Food Sci. Technol. J. 10 (1977) 109.

[27] M.A. Rao, J.F. Steffe, Viscoelastic Properties of Foods, Elsevier Applied Science, New York, 1992.

[28] G.E. Hibberd, N.S. Parker, Dynamic viscoelastic behaviour of wheatflour doughs IV, Rheol. Acta 14 (1975) 151.

[29] L.L. Navicks, R.A. Anderson, E.B. Bagley, B.K. Jasberg, Viscoelastic properties of wheat flour doughs: variation of dynamic moduli with water and protein content, J. Texture Stud. 13 (1982) 249.

[30] J. Wang, C.M. Rosell, C.B. Barber, Effect of the addition of different fibres on wheat dough performance and bread quality, Food Chem. 79 (2002) 221.

[31] R.W. Jones, S.R. Erlander, Interactions between wheat proteinsand dextrans, Cereal Chem. 44 (1967) 447. 